\title{
DIAGNÓSTICO SOCIOECONÔMICO EM BACIAS HIDROGRÁFICAS: BACIA
}

\author{
Telma Teixeira \\ Doutor em Engenharia Civil/ UEFS \\ telma@uefs.br
}

Monica Pertel

Doutor em Engenharia Civil/ UFRJ

monicapertel@poli.ufrj.br

\section{Moema V. Acserald}

Doutor em Engenharia Civil/ UFRJ

moemava@gmail.com

\section{Frank Pavan de Souza}

Doutor em Engenharia Civil/ UFRJ

frankpavan@gmail.com

\section{Ana Silvia Pereira Santos}

Doutora em Engenharia Civil/UERJ

ana.pereira@uerj.br

\section{RESUMO}

Os diagnósticos socioeconômicos em Bacias Hidrográficas são elementos que compõem os Planos de Bacias, sistematizando dados e informações relacionadas a padrões históricos e culturais de ocupação da região, dinâmica populacional e produtiva e estrutura de saneamento ambiental. Como unidades de gestão, as Bacias são delimitadas a partir de critérios topográficos que não coincidem com as unidades de levantamento de dados, tornando necessário o desenvolvimento de procedimentos metodológicos específicos para a determinação da amostra. Este problema é ainda mais relevante em áreas de pouca representatividade econômica e populacional, sem elementos específicos que estimulem estudos dirigidos. Diante dessas questões, o presente artigo apresenta uma proposta de orientações metodológicas para a elaboração de diagnósticos socioeconômicos em Bacias Hidrográficas, aplicando os procedimentos às Bacias Hidrográficas do Rio das Contas cujos limites estão totalmente inseridos no Estado da Bahia. Os resultados evidenciam que a partir de dados secundários é possível a suficiente caracterização da região para orientação na elaboração do Plano de Bacia.

Palavras-chave: Recursos Hídricos; Diagnóstico Socioeconômico; Gestão.

\begin{abstract}
Socioeconomic studies in watershed are elements of Watershed Plan, that presents systematized data and information, related to historical and cultural patterns of territorial occupation, demographic aspects, production's dynamics and environmental sanitation structure. As management units, the basins are bounded from topographical criteria not equivalent to the units of data collection, requiring the development of specific methodological procedures in order to determinate the sample. This is a more important problem in areas of low economic and population importance that does not present specific elements that stimulate directed studies. Considering these issues, this paper proposes methodological guidelines for socioeconomic studies in watershed that are applied to the 'Rio das Contas' watersheds whose boundaries are completely inserted in the State of Bahia. The results show that from secondary data it is possible to characterize the region in order to elaborate its watershed plan.
\end{abstract}

Keywords: Water resources; Socioeconomic diagnosis; Management. 


\section{INTRODUÇÃO}

A implementação do processo de gestão em bacias hidrográficas após a Lei das Águas de 1997 trouxe à tona diversas questões conceituais, institucionais e metodológicas. O termo 'bem público' usado para definir a água bruta foi discutido sob a ótica de propriedade e acessibilidade, confrontando a ciência jurídica e econômica. A expressão 'valor econômico' foi reduzida a 'preço' e modelos microeconômicos baseados nas relações de mercado foram desenvolvidos como propostas para a cobrança. No âmbito institucional, ainda não foram solucionados conflitos decorrentes da concepção de gestão integrada, cidadã e participativa dos Comitês de Bacia, criados como unidades de gestão sem poder deliberativo, e a estrutura burocrática técnica e administrativa na qual se baseia o planejamento territorial. Inúmeros trabalhos já foram apresentados para discutir essas questões e algumas sistematizações e convergências foram pactuadas observando a evolução das discussões e propostas no contexto internacional (BARRAQUE, 1997; BISWAS, 2004; HANEMANN, 2006; MARCOUILLER e COGGINS, 1999a e 1999b; ROGERS et alii, 1998) e nacional (FADUL et al, 2013; MOTTA, 2006; RIBEIRO et al. 1999; TEIXEIRA e AZEVEDO, 2013).

Enquanto instrumentos de gestão, os Planos de Bacia são planos diretores que contextualizam a situação da Bacia e norteiam projetos de longo prazo considerando aspectos diversos como situação dos recursos hídricos, padrões históricos e demográficos de uso e ocupação do solo e estrutura das atividades produtivas. Por essa razão, consubstanciando os Planos de Bacia, são elaborados diagnósticos socioeconômicos que retratam além dos padrões culturais e sociais das comunidades presentes, as formas de uso da água e as demandas hídricas das atividades econômicas da região. O objetivo é sistematizar um conjunto de informações que fundamentem projetos de obras e melhorias, bem como indiquem a disponibilidade qualiquantitativa de recursos hídricos para atender a demanda existente e projetos futuros, priorizando sempre o abastecimento humano e a dessedentação animal, conforme legalmente estabelecido.

Nesse sentido, o estudo socioeconômico em bacias hidrográficas consiste no levantamento e sistematização de dados e informações diversas, circunscritas à área de influência da bacia com fins de alicerçar decisões diretamente relacionadas ao corpo hídrico e seus afluentes. Contudo, o processo de compilação de indicadores revela questões metodológicas relacionadas a convergência de espaços de planejamento, gestão e estudo.

Fundamentalmente o problema decorre da delimitação da área da Bacia através de critérios topográficos, baseados em um sistema conectado de cursos d'água que não coincide com as unidades de pesquisa e levantamento de dados pelos órgãos nacionais e/ou estaduais de estatística como o Instituto Brasileiro de Geografia e Estatística (IBGE). Dessa forma, associando-se as contradições e fragilidades institucionais, operacionais e administrativas do modelo conforme apontadas por Fadul et al (2013) e Porto e Porto (2008), verifica-se ainda a necessidade de gerir a inserção parcial de unidades de pesquisa na Bacia, em escalas diversas, decidindo acerca da inclusão ou exclusão da base de dados para levantamento e elaboração dos estudos.

Considerando essas dificuldades, no presente artigo, discute-se um método de tratamento de dados secundários a partir de critérios específicos para estudos socioeconômicos em Bacias Hidrográficas que permita a elaboração de um diagnóstico para esse recorte espacial. Esta proposta permite viabilizar os estudos em áreas de extensão territorial diversas mas com pouca representatividade econômica para as quais não são frequentemente realizados levantamento de dados específicos.

Assim, na sequência a esta introdução, discutem-se procedimentos metodológicos a serem adotados em estudos socioeconômicos em bacias hidrográficas tendo em conta a não coincidência entre os limites geográficos da área de drenagem e os limites político-administrativos definidos para a coleta e divulgação de dados pelos órgãos de pesquisa. Em seguida é apresentado um breve relato do processo de implantação da gestão de recursos hídricos no Estado da Bahia. Também nesta seção, articulando a proposta metodológica desenvolvida são apresentados elementos básicos pertinentes ao diagnóstico socioeconômico nas Bacias Hidrográficas do Rio das Contas, inteiramente inserida no Estado da Bahia. 


\section{METODOLOGIA}

Um diagnóstico socioeconômico é um instrumento de planejamento e gestão governamental que busca sistematizar de forma estruturada, dentro de um contexto espacial e temporalmente limitado, informações, dados e indicadores que revelem características diversas de um determinado grupo social e seu entorno. Jannuzzi (2005) aponta como características básicas para a escolha dos indicadores, entre outros, os aspectos de:

- Confiabilidade;

- Transparência metodológica;

- Relevância;

- Desagregabilidade populacional e territorial.

Os dois primeiros aspectos inferem diretamente na escolha da fonte das informações e dados a serem levantados, motivo pelo qual, na ausência de volumosos recursos para uma consistente pesquisa de campo, adota-se como princípio a utilização de dados secundários provenientes de pesquisas elaboradas por grandes institutos como o IBGE e órgãos estatísticos e secretarias estaduais e municipais, cujos procedimentos metodológicos encontram-se consolidados, atualizados e adequados as demandas dos gestores. Pertinente afirmar que mesmo quando do levantamento de dados diretos através de pesquisas amostrais ou mesmo censitárias, faz-se uso de dados secundários que permitem o acompanhamento histórico das variáveis e indicadores, úteis a elaboração de prognósticos e, consequentemente, o planejamento. Dessa forma, o uso das estatísticas oficiais asseguram a confiabilidade e transparência metodológica requeridos pelo estudo e a sua disponibilidade em séries temporais possibilitam projeções consolidadas.

Os dados assim disponibilizados apresentam-se em distintos níveis de desagregação, respeitando a divisão político-administrativa nacional (distrito federal, estados, municípios e distritos) de forma a permitir agregações espaciais (regiões metropolitanas ou grandes regiões) em razão de interesses específicos. Válido esclarecer que no âmbito das grandes pesquisas, quando da realização dos Censos, os distritos são divididos em "setores censitários" que representam unidades de coleta de informações para a pesquisa, não se constituindo em unidades administrativas. A definição e delimitação destes baseia-se no número de domicílios (entre 250 e 350 na área urbana e entre 150 e 250 na área rural) visando a operacionalização na coleta de dados, motivo pelo qual não são fixos e coincidentes de um Censo para o outro.

Em consequência dessa delimitação espacial na apresentação dos resultados das pesquisa, verifica-se parcial incompatibilidade no levantamento de informações que consubstanciem a elaboração de um diagnóstico socioeconômico para o processo de gestão em bacias hidrográficas que, apesar de serem unidades de planejamento e gestão, não possuem contornos espacialmente definidos e coincidentes com as unidades político-administrativas de forma agregada ou isolada. Diante de tal fato, as estatísticas relacionadas aos aspectos socioeconômicos, que de forma geral tem os municípios como nível mais desagregado de pesquisa e apresentação dos dados, devem ser preliminarmente tratadas do ponto de vista de filtro metodológico com o intuito de reduzir ao máximo as inconsistências e assegurar a relevância das informações apresentadas no estudo para o planejamento da Bacia.

O primeiro passo consiste na escolha dos temas a serem abordados no diagnóstico e nas variáveis a serem levantadas, tendo em conta informações relevantes para o estudo do uso dos recursos hídricos para captação, consumo e diluição de efluentes na forma de 'água bruta' como é designado o recurso hídrico em sua forma natural, sem tratamento, objeto de gestão dos Comitês de Bacia. Os principais usuários agrupamse em 4 classes distintas de acordo com os tipos de usos consumptivos: saneamento (abastecimento e esgotamento sanitário); agricultura (irrigação); pecuária (dessedentação animal) e; indústria (insumo e/ou matéria-prima). Nesse sentido, para elaboração do diagnóstico socioeconômico da bacia, podem ser indicados como temas indispensáveis ao estudo, os seguintes: 
a) Padrões históricos e culturais: no processo de exploração e ocupação de terras, os recursos hídricos sempre exerceram grande importância, determinando a fixação de um determinado agrupamento humano com garantia de água para consumo pessoal e desenvolvimento de atividades produtivas. Assim, as informações de padrões históricos e culturais permitem identificar as formas de interação das comunidades com os seus recursos hídricos ao longo do tempo, explicando atuais padrões e conflitos de uso;

b) Dinâmica demográfica: o uso da água para a manutenção da vida humana e animal é considerado prioritário no processo de gestão. Dessa forma, compreender a dinâmica populacional, seu processo de concentração urbana ou rural, sua evolução quantitativa e as projeções estimadas para as próximas décadas, constitui elemento fundamental para compreensão e avaliação das necessidades presentes e futuras sem prejuízo dos demais usos;

c) Dinâmica das atividades produtivas: agricultura, pecuária e indústria utilizam o recurso hídrico em quantidades e padrões de qualidade distintos que podem ser alterados de acordo com o desenvolvimento tecnológico que permita o uso correto do método de irrigação ou a reutilização de águas de processos. Conhecer os usos produtivos mais importantes em uma Bacia permite a construção de um plano mais adequado à estrutura vigente e perspectivas apontadas, não limitando o desenvolvimento econômico da região;

d) Estrutura de Saneamento: o abastecimento humano de forma regular, com água tratada e adequada ao consumo permanece como um desafio sendo objeto frequente de discussões. As instalações atualmente existentes são insuficientes e ineficientes, com perdas na distribuição em índices alarmantes. Na outra ponta do sistema, o esgotamento sanitário também apresenta sérios problemas, não apenas relacionados a abrangência do serviço de coleta de esgoto, mas também quanto a falta de tratamento destes, previamente ao descarte nos corpos hídricos.

Para elaboração de um conjunto de informações que abordem os temas listados, em uma segunda etapa do processo, são selecionadas as fontes de dados que permitem desagregação econômica e populacional necessária e o mais atualizada possível. Verifica-se que as pesquisas do IBGE (Censo Demográfico, Pesquisas Agrícola e Pecuária Municipais e Plano Nacional de Saneamento Básico, entre outras) associadas aos Diagnósticos do Sistema Nacional de Informações de Saneamento (Snis) disponibilizam estatísticas ao nível municipal que atendem a esses requisitos.

Nesse ponto deve ser considerado que em áreas de relevância econômica ou demográfica, objeto de atenção de estudos mais específicos, diversas estatísticas são também disponibilizadas podendo auxiliar a elaboração do diagnóstico socioeconômico da Bacia. Contudo, regiões menos representativas demograficamente e/ou com pouca influência nos índices de produtividade regionais e/ou nacionais carecem de estudos dirigidos ou mesmo com maior desagregação territorial, dificultando o levantamento e sistematização de condições segundo um recorte espacial diferenciado. Esses argumentos corroboram a presente proposta de sistematização.

Quando da etapa de coleta dos dados, atenta-se para o nível territorial para o qual estes são divulgados, expondo os problemas de incompatibilidade espacial já citados. A inserção parcial de municípios na área de drenagem, torna necessária a avaliação prévia de algumas características para definição da amostra, a saber:

a) Percentual de inserção da área do município na Bacia: este é o primeiro critério para a possível exclusão de municípios parcialmente inseridos na Bacia; a priori, eliminam-se os de baixa representatividade, aqui delimitado como $5 \%$ de nível de inserção territorial, mantendo aqueles com mais de $70 \%$ do território inserido. Os demais, situados na faixa de 5 a $70 \%$ de inserção são analisados considerando as demais características aqui apresentadas;

b) Localização da sede municipal em relação à Bacia: municípios distantes das capitais tem níveis distintos de concentração espacial. Nesse sentido, a localização da sede dentro ou fora da Bacia é um indicador para a representatividade populacional na área de estudo;

c) Taxa de urbanização do município: havendo sede municipal dentro (fora) dos limites da Bacia e elevada (baixa) taxa de urbanização, pode-se inferir que o maior (menor) contingente populacional pertence à região;

d) Localização de distritos industriais ou polos econômicos: havendo informações que georreferenciem a atividade econômica em relação à Bacia, estas são também incluídas como elementos de apoio a decisão; 
e) Setor de atividade econômica de maior importância: os dados setorialmente desagregados do Valor Adicionado Bruto (VAB) dos municípios indicam se a riqueza gerada na agropecuária é ou não representativa no Produto Interno Bruto (PIB) do município. Esse critério associa-se àqueles de localização da sede e taxa de urbanização para corroborar a decisão, indicando a zona de maior geração de riqueza (rural ou urbana).

Na delimitação da amostra, deve ser sempre considerado que o objetivo do estudo é dar suporte ao processo de gestão em Bacias Hidrográficas. Assim, sendo o abastecimento humano e a dessedentação animal os usos prioritários e mais representativos em áreas pouco desenvolvidas economicamente, as variáveis populacionais acabam por tornar-se as mais relevantes no processo. Baseando-se nesses argumentos, na próxima seção seleciona-se a área de estudo para a Bacia do Rio das Contas (Bahia), discutindo também os elementos básicos do diagnóstico socioeconômico obtidos com a amostra.

\section{RESULTADOS}

\subsection{Seleção da amostra para estudo}

A BHRC, localizada na RPGA (Região de Planejamento e Gestão das Águas) VIII, está completamente inserida em território baiano, na porção centro-sul do Estado estendendo-se por uma área de $55.334 \mathrm{~km} 2$ e banhando total ou parcialmente 81 municípios que ocupam uma área superior a $70 \mathrm{mil} \mathrm{km}^{2}$, extrapolando assim em mais de $30 \%$ a área de drenagem.

Evidenciando os problemas relacionados a compatibilização de limites geográficos para o estudo, constata-se que apenas 35 entre os 81 municípios estão integralmente inseridos na Bacia, sendo que outros 5 tem menos de $5 \%$ da sua área dentro dos limites. Com base em critérios de relevância estes últimos são excluídos da análise socioeconômica para elaboração do diagnóstico. Na sequência, considerando as orientações estabelecidas na seção precedente manteve-se na amostra os 55 municípios com mais de $70 \%$ de território inserido na RPGA. Os demais foram analisados considerando os critérios estabelecidos na seção anterior e como resultado, foram excluídos:

- 5 municípios com baixa inserção territorial e sede fora da bacia (Apuarema, Érico Cardoso, Ilhéus, Marcionílio Souza e Mucugê);

- 5 municípios com concentração populacional em área urbana e sede distante dos limites das bacias (Almadina, Camamu, Jaguaquara, Vitória da Conquista e Uruçuca). Entre esses municípios verificou-se ainda que a setor de maior representatividade na geração de riqueza era o de 'Serviços e Administração Pública' que são quase que totalmente concentrados nos agrupamentos urbanos, ratificando assim a exclusão através do critério de localização da sede.

Assim, considerando os critérios estabelecidos, foram selecionados 66 municípios que constituíram a base para o levantamento dos dados e informações socioeconômicas descritas a seguir.

\subsection{Dinâmica demográfica}

O povoamento na região da Bacia tem origens em povos indígenas dominados no processo de colonização ainda no século XVIII. A extração de minérios, a fertilidade do solo e a abundância de água eram os elementos que atraiam sobretudo bandeirantes, entre os quais destacou-se João Alves da Costa, figura relevante no desbravamento entre os séculos XVII e XVIII, que dizimou povos indígenas de diferentes etnias para consolidação da conquista e colonização (SEI, 2003).

As condições favoráveis que atraíram os colonizadores foram determinantes para a fixação da população na área que já nos anos de 1980 ultrapassava o quantitativo de 1 milhão de habitantes. Os municípios selecionados para caracterização da Bacia, por ocasião do Censo Demográfico de 2010 totalizavam 1.274 .327 pessoas, sendo que o conjunto de municípios com mais de $90 \%$ de área inserida representavam $76,70 \%$ desse total (IBGE, 2011). 
Contendas do Sincorá e Iramaia possuem a menor densidade demográfica do grupo $\left(4,77 \mathrm{hab} / \mathrm{km}^{2}\right.$ e $6,16 \mathrm{hab} / \mathrm{km}^{2}$, respectivamente), enquanto os extremos opostos são Ipiaú $\left(166,05 \mathrm{hab} / \mathrm{km}^{2}\right)$ e Ubaitaba $\left(114,25 \mathrm{hab} / \mathrm{km}^{2}\right)$. Todos esses indicadores bem distantes daquele apresentado pelo Estado da Bahia $(24,82$ $\left.\mathrm{hab} / \mathrm{km}^{2}\right)$ e pelo conjunto da RPGA $\left(21,29 \mathrm{hab} / \mathrm{km}^{2}\right)$. Contudo, deve ser advertido que em todas essas situações verificam-se extensas áreas totalmente desocupadas em razão de florestas ou mesmo áreas de produção agropecuária.

Embora seja uma região cujas atividades estão mais popularmente relacionadas à produção rural, as taxas de urbanização dos municípios acompanham a alta média nacional e ultrapassa $90 \%$ em Ipiaú, Jequié e Coaraci (IBGE, 2011). Certamente, um processo associado à crise na produção agropecuária e sua mecanização, fatores que interferem negativamente no número de empregos na zona rural promovendo o êxodo em direção à sede municipal. $\mathrm{O}$ deslocamento populacional foi constante e gradativo ao longo das últimas décadas (Figura 1), não apresentando "saltos" que possam ser atribuídos a eventos econômicos ou populacionais de impacto mais momentaneamente brusco. Como resultado, elevaram-se as pressões de demanda por serviços públicos essenciais como abastecimento de água e esgotamento sanitário, e também sobre os demais serviços básicos, como manejo de resíduos sólidos, energia, transporte e comunicações. A não ocorrência de "saltos" pode induzir a um processo de acomodação das infraestruturas que se ajustam gradualmente a modificação do contexto populacional expondo o esgotamento e/ou insuficiência apenas quando a situação torna-se crítica.

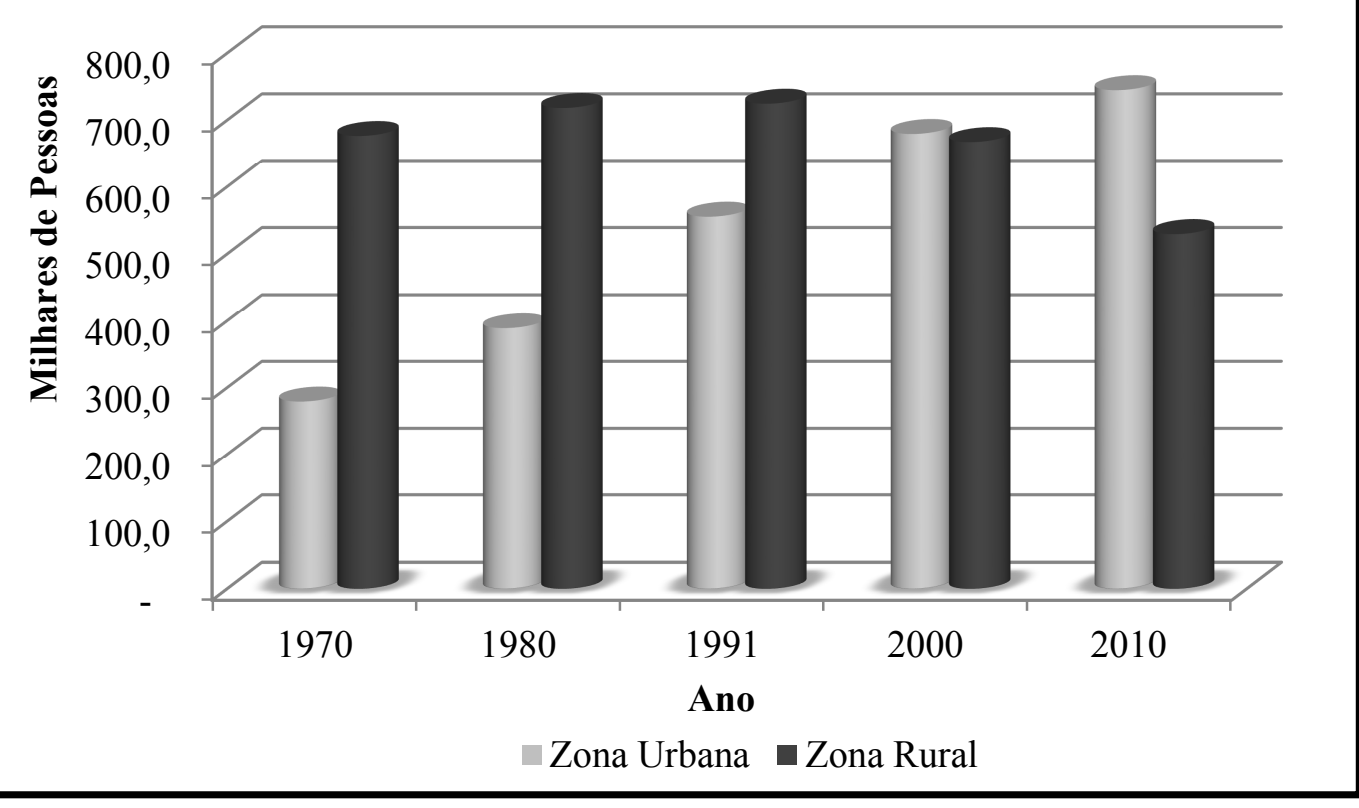

Figura 1: Evolução da população residente nos municípios da RPGA do Rio das Contas segundo localização do domicílio. 1970-2010

Quanto as faixas etárias a distribuição da população residente é também semelhante à do Estado da Bahia, sem contudo grandes desproporcionalidades (IBGE, 2011). As proporções atuais são resultado de um processo de envelhecimento gradativo da população ao longo das últimas cinco décadas, que segundo estudos da Superintendência de Estudos Econômicos e Sociais da Bahia (SEI) são provocados pela menor taxa de fecundidade e migração populacional. A população em sua grande maioria jovem nos anos 70 (57,14\% com até 19 anos de idade) transformou-se em prioritariamente adulta $(53,42 \%$ com entre 20 e 59 anos de idade) na data do Censo Demográfico, com duplicação do percentual de pessoas com 60 anos ou mais (Figura 2). 


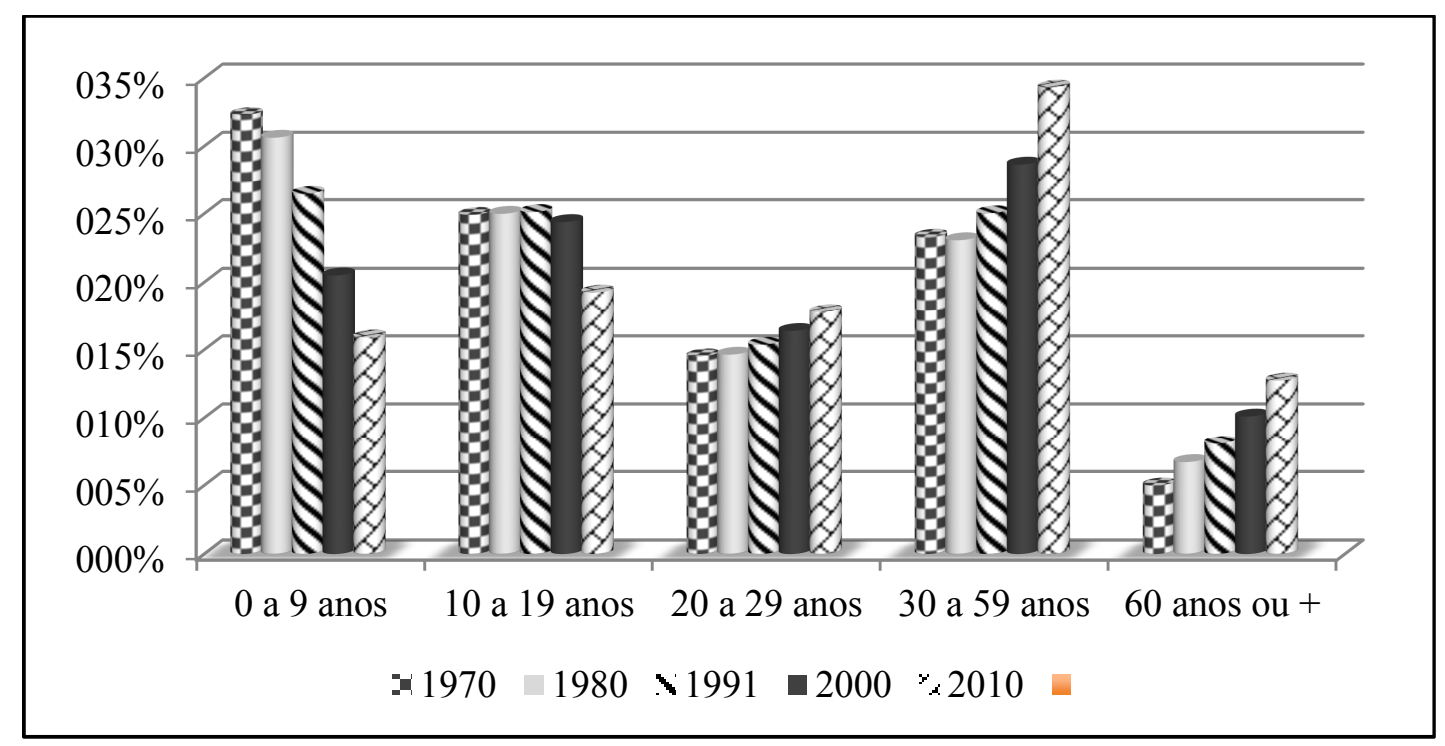

Figura 2: Evolução da população residente nos municípios da RPGA do Rio das Contas segundo grupos de faixa etária.1970-2010

As projeções populacionais calculadas pela SEI com base nos dados do Censo de 2010 indicam um crescimento na zona urbana a uma taxa geométrica de aproximadamente $1 \%$ até 2030 , com redução similar na zona rural $(1,02 \%)$. Distribuídas segundo grandes grupos etários, estas projeções evidenciam um forte movimento de envelhecimento da população. Os jovens, indivíduos com até 14 anos, que em 2010 representavam $26 \%$ dos habitantes, tem previsão de proporção reduzida a $18 \%$ em 2030, ao tempo em que os idosos (65 anos ou mais) crescem de 9\% a 13\% (Tabela 1). Como resultado, ao longo dos anos ocorre uma redução da 'Razão de Dependência' dos jovens e aumento desta taxa entre os idosos. Válido salientar que embora esta seja uma tendência apresentada pelas estatísticas nacionais, essa mudança em municípios de pouca infraestrutura de serviços básicos pode ser respondida em períodos ainda mais longos em decorrência da falta de recursos, agravando a situação.

Tabela 1: Estimativas Populacionais Segundo Grandes Grupos Etários. 2010-2030

\begin{tabular}{ccccc}
\hline Ano & $0-14$ anos & $15-64$ anos & $\begin{array}{c}65 \text { anos ou } \\
\text { mais }\end{array}$ & Total \\
\hline 2015 & 285,51 & 809,37 & 120,87 & $1.215,74$ \\
2020 & 263,98 & 833,75 & 133,17 & $1.230,90$ \\
2025 & 249,99 & 843,95 & 149,43 & $1.243,37$ \\
2030 & 229,97 & 857,56 & 165,96 & $1.253,50$ \\
\hline
\end{tabular}

Estas projeções servem como base para as estimativas de demanda hídrica para abastecimento humano e análise da infraestrutura de saneamento da região. O calculo é feito considerando coeficientes médios diários de consumo para atender as necessidades de bebida, cozimento, asseio corporal, lavagem de roupa e limpeza em geral. Estes variam entre as zonas urbana e rural e também entre faixas populacionais dos municípios incorporando assim elementos associados a infraestrutura disponível. O 'Plano de Aproveitamento Integrado dos Recursos Hídricos do Nordeste do Brasil' elaborado pela Sudene em 1980 e revisado e corroborado pelo Projeto Áridas (FERREIRA FILHO, 1994) apresenta coeficientes específicos para o nordeste. 
Quadro 1: Coeficientes de demanda hídrica para abastecimento humano

\begin{tabular}{|c|c|c|}
\hline \multirow{2}{*}{ Zona } & População & $\begin{array}{c}\text { Coeficiente de } \\
\text { Demanda }\end{array}$ \\
\hline \multirow{4}{*}{ Urbana } & até 5.000 & $145 \mathrm{l} / \mathrm{hab} / \mathrm{dia}$ \\
\cline { 2 - 3 } & de mais de 5.000 até 10.000 & $185 \mathrm{l} / \mathrm{hab} / \mathrm{dia}$ \\
\cline { 2 - 3 } & de mais de 10.000 até 20.000 & $230 \mathrm{l} / \mathrm{hab} / \mathrm{dia}$ \\
\cline { 2 - 3 } & de mais de 20.000 até 100.000 & $270 \mathrm{l} / \mathrm{hab} / \mathrm{dia}$ \\
\cline { 2 - 3 } & de mais de 100.000 até 500.000 & $330 \mathrm{l} / \mathrm{hab} / \mathrm{dia}$ \\
\cline { 2 - 3 } & mais de 500.000 & $460 \mathrm{l} / \mathrm{hab} / \mathrm{dia}$ \\
\hline Rural & & $270 \mathrm{l} / \mathrm{hab} / \mathrm{dia}$ \\
\hline
\end{tabular}

Fonte: Ferreira Filho, 1994.

Aplicando-se esses coeficientes sobre as estimativas populacionais obtêm-se uma demanda hídrica

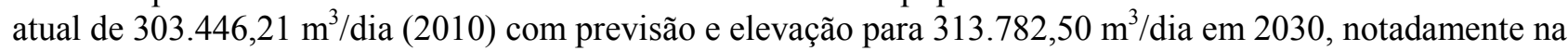
zona urbana onde o crescimento populacional é mais acentuado (Tabela 2).

Tabela 2: Projeção de demanda hídrica para abastecimento humano na BHRC. 2015-2030

\begin{tabular}{ccccc}
\hline \multirow{2}{*}{ Ano } & \multicolumn{2}{c}{ Zona Urbana } & \multicolumn{2}{c}{ Zona Rural } \\
\cline { 2 - 5 } & $\begin{array}{c}\text { População } \\
(\text { mil habitantes })\end{array}$ & $\begin{array}{c}\text { Demanda Hídrica } \\
\left(\mathrm{m}^{3} / \text { dia }\right)\end{array}$ & $\begin{array}{c}\text { População } \\
(\text { mil habitantes })\end{array}$ & $\begin{array}{c}\text { Demanda Hídrica } \\
\left(\mathrm{m}^{3} / \text { dia }\right)\end{array}$ \\
\hline 2015 & 730,65 & $176.705,12$ & 485,09 & $130.974,50$ \\
2020 & 772,19 & $186.560,17$ & 458,72 & $123.853,83$ \\
2025 & 808,81 & $195.186,40$ & 434,56 & $117.330,83$ \\
2030 & 840,30 & $202.218,19$ & 413,20 & $111.564,31$ \\
\hline
\end{tabular}

\subsection{Dinâmica das atividades produtivas}

Nos municípios que formam a RPGA de Rio das Contas manteve-se a vocação agrícola já identificada no processo de povoamento, sem que houvesse transformações no sentido de uma maior diversificação da produção. Os municípios de Jequié e Vitória da Conquista (este fora da seleção previamente estabelecida) desenvolveram-se como cidades-polo, ou seja, centros urbanos distantes da capital do estado que exercem grande influência nos seus arredores.

No âmbito dos indicadores econômicos de produção de riqueza, dados do Produto Interno Bruto (PIB) dos municípios que representam as BHRC somaram em $2012 \mathrm{R} \$ 8,85$ bi (preços correntes), equivalente a 5,28\% do PIB do Estado (R $\$ 167,73$ bi) sendo Jequié, seguido de Brumado, os municípios de maior importância econômica na região com participações de $1,15 \%$ e $0,42 \%$ no total da Bahia e $23,21 \%$ e $8,47 \%$ na RPGA, respectivamente. Contendas do Sincorá e Lafaiete Coutinho são os de menor representatividade econômica participando com $0,01 \%$ no PIB da Bahia. A baixa geração de riqueza da região é observada quando verifica-se a composição setorial do VAB que denuncia a elevada contribuição dos setores de serviços e administração pública $(70,69 \%$ do total) com pouca contribuição da agropecuária e indústria. 
Apesar da pouca riqueza gerada, estudos da SEI (2003) corroboram a importância da pecuária no processo de ocupação da região e a pouca diversificação de culturas. A extração do látex, o cultivo do café, do algodão e do cacau foram e continuam sendo menos representativos para a economia da região, onde a agricultura permanece pouco diversificada. $\mathrm{O}$ algodão, que já foi importante na região, atualmente não é registrado em nenhum dos municípios e a borracha (látex coagulado) representa menos de $1 \%$ da riqueza gerada pelo setor e da áreas plantada e destinada a colheita (IBGE, 2015b).

Quanto a pecuária, dados da Pesquisa Pecuária Municipal (PPM) do IBGE confirmam a representatividade da criação animal da região diante dos diversos rebanhos do Estado da Bahia. 19\% dos muares e $17 \%$ dos suínos criados no Estado encontram-se na BHRC. Os municípios de Brumado, Ibicuí, Itagibá, Jequié, Manoel Vitorino e Nova Canaã concentram aproximadamente $30 \%$ do rebanho bovino e $50 \%$ dos bubalinos da RPGA (IBGE, 2015a). No processo de formação histórica e econômica dos municípios da BHRC, a expansão da produtividade pecuária ocorreu com aumento da área de pastagem como elemento determinante, havendo poucas inserções relacionadas a melhorias tecnológicas e gerenciais, acarretando um fenômeno de 'pecuarização' da terra.

Para o ao setor industrial, identifica-se na RPGA o Distrito Industrial de Jequié, com área de $2.489,26$ mil m2 e abrigando 31 empresas já instaladas, com um registro de 7.600 pessoas empregadas (SICM/SUDIC, 2013?). O Distrito localiza-se próximo ao perímetro urbano do município de Rio de Contas, podendo ser acessado via sistema viário através das BR 116 e BR 330. Distante 190km do Distrito, o Porto de Malhados em Ilhéus é o ponto mais próximo para escoamento dos produtos provenientes dos ramos de plásticos e produtos de matérias plásticas, calçados, vestiário e artefatos de Tecidos e produtos alimentares. O Relatório informa que no período analisado todos os 8 registros empresariais de implantação ou ampliação de unidades foram localizados no município de Jequié, com investimentos privados da ordem de R \$ 45,3 milhões, equivalente a menos de $0,2 \%$ dos projetos de todos os Distritos Industriais do interior do Estado. O Distrito recebeu ainda obras de melhorias de Manutenção e Limpeza das Vias (R\$ 1 milhão) e a construção de 5 galpões beneficiando as empresas Branyl, Guelê, Mauricio Almeida, Marcom e Miramar, com valor contratual de R \$ 8 milhões.

Contudo, o atual contexto apresenta perspectivas de mudanças no médio prazo em razão de projetos relacionados ao setor de extração mineral. O diagnóstico setorial apresentado pelo Instituto Euvaldo Lodi (Sistema Fieb) através do documento "Política Industrial da Bahia: estratégias e proposições" (IEL, 2011) destaca o Projeto Pedra de Ferro no município de Caetité, com previsão de escoamento da produção através da Ferrovia de Integração Oeste-Leste (Fiol) até o terminal de embarque de Ponta da Tulha (terminal privativo localizado em uma estrutura compartilhada do Porto Sul). O principal produto a ser transportado pela Fiol será o minério de ferro produzido na mina de Caetité, explorado pela empresa Bamin. Ainda segundo o documento, são diversos projetos ligados a exploração do minério de ferro e a estrutura ferroviária a ser implementada, tornando o projeto da Bamin estruturante e essencial para o próprio Porto Sul.

Também no setor de extração mineral, destaca-se o Projeto Santa Rita localizado em Itagibá, da empresa australiana Mirabela Nickel, com investimentos da ordem de US\$ 450 milhões, construção iniciada em 2006 e inaugurada em 2009. A exploração ocorre na maior jazida de níquel de sulfetado descoberta no mundo na última década, funcionando a céu aberto, e com potencial para transformar a Bahia no terceiro maior produtor nacional do minério, atrás de Goiás e Pará. Está prevista ainda a produção de 9 mil toneladas/ano de cobre pelo Projeto. Identifica-se ainda a mina de ferro da Gerdau localizada em Jussiape e o Projeto Talco de Umburanas em Brumado, onde se encontra também uma unidade de cimento Portland pertencente ao Grupo Cimpor.

Contudo, a maior aposta no setor relaciona-se a mina de vanádio localizada no município de Maracás. O minério é matéria prima principalmente utilizada em indústrias de aços especiais nas áreas de óleo e gás, materiais cirúrgicos, turbinas eólicas e ferrovias de alta velocidade. A mina possui vanádio com o grau mais elevado do mundo e está posicionado para ser o produtor de menor custo no mercado, produzindo para Europa, Estados Unidos, Japão e Coréia do Sul. O empreendimento ocupa uma área de 28.587 hectares, localizado na rede de drenagem da margem esquerda do rio das Contas, a montante do reservatório da barragem de Pedra. A produção média anual, baseada em uma vida útil da mina de 29 anos, está estimada em 11,4 mil toneladas de pentóxido de vanádio $\left(\mathrm{V}_{2} \mathrm{O}_{5}\right)$. 
O que se observa é que a dinâmica do setor industrial da região pauta-se em investimentos de pequeno porte revestidos de grandes expectativas associadas a geração de emprego e renda decorrentes da intensificação da extração mineral na região e do funcionamento do Porto Sul, com perspectivas de transformar o Estado da Bahia em grande produtor minério de ferro, níquel e vanádio. Contudo, deve ser ponderado que projetos dessa magnitude por vezes apresentam informações desencontradas relacionadas a geração de emprego e renda. É fato que no processo de construção a geração de postos de trabalho é volumosa e permite a fácil inserção de mão de obra local, sem grandes demandas de qualificação. Entretanto, depois de implantado, a operacionalização do projeto reduz suas necessidades de trabalhadores ao tempo em que eleva as exigências de capacitação. É lícito também afirmar que o projeto permite o desenvolvimento de potenciais econômicos ainda não explorados ou incentivo e novo fôlego aos já existentes. Porém, em uma região historicamente alicerçada na atividade rural, os fatores relacionados à sustentabilidade ambiental não podem ser colocados como secundários.

\subsection{Saneamento ambiental: abastecimento de água e esgotamento sanitário}

A análise de saneamento ambiental a partir de uma abordagem que privilegie o contexto socioeconômico tem como intuito verificar a adequação e/ou eficiência dos sistemas de saneamento (abastecimento e esgotamento principalmente) nas comunidades envolvidas. Na elaboração de planos de bacias, essas informações fornecem subsídios para orientar as atividades de identificação de demandas de projetos de saneamento a partir do conhecimento dos problemas pontuais, visto que aspectos mais específicos concernentes à qualidade de corpos de água extrapolam o recorte espacial de municípios e grupos populacionais.

Informações básicas e detalhadas relacionadas aos serviços de abastecimento de água e esgotamento sanitário para municípios brasileiro são providas pela Secretaria Nacional de Saneamento Ambiental (SNSA) do Ministério das Cidades desde o ano de 1995. Sete anos após o início destes relatórios, em 2002, a pesquisa foi ampliada incluindo também o Diagnóstico de Manejo de Resíduos Sólidos Urbanos. Estas informações são divulgadas através do Sistema Nacional de Informações de Saneamento (Snis) que é o resultado de duas etapas: na primeira, a Secretaria encaminha convite ao município, solicitando a sua participação na coleta de dados. Na sequência, aceito o convite, o prestador responsável pelos serviços no município preenche os questionários do Sistema. Observa-se assim que o processo é autodeclaratório e voluntário, não se estendendo a todos os municípios brasileiros.

Alternativamente, o IBGE divulgou em 2008 a Pesquisa Nacional de Saneamento Básico (PNSB), de caráter censitário para todos os 5.565 municípios brasileiros, coletando junto às prefeituras e empresas prestadoras de serviços de saneamento informações que permitissem de forma simultânea a avaliação das condições de oferta dos serviços, análise das condições ambientais e suas implicações com a qualidade de vida da população. A pesquisa, realizada em parceria com o Ministério das Cidades, além das informações de abastecimento de água, esgotamento sanitário e manejo de resíduos sólidos, traz também dados acerca do manejo de águas pluviais nos municípios. Muitas das informações e dados disponibilizados pela PNSB abrangem também o ano de 2000, quando foi realizada a primeira edição com os 5.507 municípios existentes.

Assim, de forma geral, pode-se afirmar que as informações sobre abastecimento de água, esgotamento sanitário e manejo de resíduos sólidos nos municípios brasileiros, são disponibilizadas em duas pesquisas nacionais.

Os resultados do Snis permitem, sobretudo, uma avaliação da estrutura institucional dos prestadores de serviços e a análise da eficiência operacional dos mesmos. A coleta inclui dados do balanço das empresas (ativo, passivo, lucros e resultados) e financeiros (receitas, despesas, investimentos), além de informações de qualidade dos serviços e dos produtos. Pode-se afirmar que a estrutura da pesquisa privilegia o conteúdo organizacional do setor, permitindo um mapeamento detalhado para análise também nesse contexto. Contudo, os Diagnósticos do Snis não se restringem a essa abordagem, pois informam também acerca da abrangência dos serviços para as diversas economias/ligações registradas em cada município pesquisado. 
Por sua vez, o PNSB do IBGE insere-se em um contexto de pesquisas de caráter privilegiadamente social, com uma metodologia reconhecida e consolidada e coleta de dados por entrevistadores especializados. A ênfase na coleta de dados é nos municípios e, em algumas situações, nos distritos e subdistritos do mesmo, não no prestador do serviço. É objeto de investigação no PNSB as ocorrências de doenças associadas ao saneamento, bem como a existência de elementos reguladores quanto a proteção de mananciais e manejo de águas pluviais. Em função da ênfase social adotada, o PNSB não fornece dados relacionados aos aspectos administrativos e financeiros dos prestadores, tais como receitas, despesas, lucros, investimentos e resultados econômico-financeiros. Adicionalmente, o caráter censitário não envolve também as informações sobre população, motivo pelo qual apenas estima-se a população atendida para o ano da pesquisa, considerando as projeções populacionais do IBGE, a média de moradores por domicílio e o número de economias/ligações ativas.

Analisando as informações censitárias do PNSB de 2008, verifica-se que todos os municípios da RPGA do rio das Contas apresentam efetivamente a existência de rede geral de abastecimento de água embora não atenda, na grande maioria dos municípios, a todos os domicílios, sendo contabilizadas 298.489 economias abastecidas na RPGA. Cada economia equivale a uma unidade abastecida, podendo ser um apartamento, unidade comercial, sala de escritório, moradia ou órgão público. O conceito de 'economia' difere do conceito de 'ligação' pois esta última pode referir-se a mais de uma 'economia'. As economias ativas abastecidas por rede geral (contribuintes regulares para o faturamento do serviço) totalizaram 270.802 unidades, sendo a quase totalidade $(90,59 \%)$ do tipo residencial.

O PNSB informa que nem toda a água distribuída nos municípios passava por algum tipo de tratamento; $219.589 \mathrm{~m} 3$ foram distribuídos, mas 33,56\% deste volume sem qualquer tratamento (IBGE, 2010).

Em dados mais recentes, o Censo Demográfico de 2010, indicaram que aproximadamente $33 \%$ dos domicílios da RPGA do rio das Contas (118.362 unidades) não se encontravam ligados à rede geral de abastecimento, utilizando outras fontes para suprir suas necessidades de água (poço, lago, rio etc.). Desse percentual, uma parcela de $6,67 \%$ informa que seriam rios, lago, açude ou igarapé as suas fontes de abastecimento, ratificando a capilaridade da rede hidrológica da região.

No que concerne à rede de esgotos, os dados do PNSB indicaram em 2008 que a coleta era realizada em apenas 35 municípios das Bacias, havendo tratamento do esgoto coletado em apenas 14 destes. No Censo Demográfico de 2010 essas informações são apresentadas considerando o número de domicílios atendidos pelo serviço, diferentemente do PNSB que considera o município como um todo sem observar a abrangência do serviço dentro do município. Os dados assim apresentados e mais atualizados indicavam que a não ligação à rede geral de abastecimento revela problemas significativo de infraestrutura que são agravados pelas informações relacionadas à existência de banheiro e/ou sanitário de uso exclusivo ou não nos domicílios. No total da RPGA, 40.463 domicílios (11,26\%) declararam em 2010 a inexistência de banheiro ou sanitário. Tal fato contribui para o agravamento das condições sanitárias e torna a população mais vulnerável às doenças relacionadas a falta ou inadequação do saneamento. Os dados do Censo revelam ainda que diante da ausência da ligação com a rede geral de esgotos 8.799 domicílios lançavam seus efluentes diretamente em rio, lago ou mar (IBGE, 2010).

Nos dados do SNIS para a RPGA do rio das Contas, apenas os municípios de Abaíra, Dom Basílio e Piatã não apresentaram informações para o Diagnóstico dos Serviços de Água e Esgoto do ano de 2013. Em conjunto, estes municípios correspondem a aproximadamente $3 \%$ dos domicílios particulares permanentes da RPGA em 2010 e da população residente no mesmo ano. Dessa forma, apesar dessas ausências, está garantida a representatividade da base de dados para as informações coletadas, mesmo diante de possíveis considerações relacionadas ao aspecto autodeclaratório da pesquisa.

A rede de água que serve aos municípios da RPGA estende-se por $3.755 \mathrm{~km}$ atendendo a 849.683 pessoas das quais $65,70 \%$ na zona urbana. A partir do conceito de 'economia', conforme aplicado pelo Censo Demográfico do IBGE, os prestadores de serviços informaram que havia 277.252 economias ativas, configurando um aumento de $2,39 \%$ em 3 anos, partindo do pressuposto de equivalência entre as pesquisas. Estas 'economias' representavam 264.163 ligações indicando assim a pequena quantidade de unidades 
(como por exemplo prédios), compartilhando a mesma ligação (SNIS, 2013). Quase 40 milhões de $\mathrm{m}^{3}$ de água foram produzidos no ano, sendo $93,82 \%$ tratado em ETA e apenas 3,68\% tratado por simples desinfecção. Os indicadores populacionais do SNIS indicam que no concernente ao número de habitantes existe uma clara deficiência no atendimento à população.

Além de pouco distribuída, existem "perdas" significativas nestes sistemas. Alerta-se que o sentido destas "perdas" não é unicamente o de perda física, como muitas vezes é confundido. Em sistemas de abastecimento público perdas significam a diferença entre o volume de água tratado e distribuído, e o volume de água faturado aos consumidores. Nesta diferença podem ser computadas, sim, as perdas físicas na rede de distribuição, mas também problemas de ligações ilegais e de falta de hidrometração, que faz com que o consumo seja simplesmente estimado, induzindo muitas vezes ao desperdício. Em 2013 os prestadores declararam perdas de quase $65 \%$ em alguns dos municípios das Bacias.

O serviço de esgotamento sanitário é mais precário do que o de abastecimento público, como ocorre em todo país. À rede de esgoto de $525 \mathrm{~km}$ estavam conectadas 57.017 ligações ativas, equivalentes a 50.848 economias, atendendo a 170.827 habitantes. Destes, 131.690 ou $77,09 \%$ do total da RPGA, unicamente no município de Jequié, responsável pela produção de $84,50 \%$ do esgoto coletado ( $7.745 \mathrm{mil} \mathrm{m3/ano).}$

Apesar da insuficiência, deve ser alertado que o panorama relacionado ao saneamento nos municípios da região encontra-se em profunda transformação nos últimos anos. Através do Programa Água para Todos (PAT) do Governo Federal, desde 2007 várias ações têm sido desenvolvidas no intuito de ampliar o acesso à água à população da zona rural e em situação de extrema pobreza de diversos municípios do Brasil. Embora o semiárido seja a principal região beneficiada com o Programa, outras localidades também receberam investimentos expressivos. Entre estas, estão todos os municípios da RPGA do rio das Contas. Os projetos dividiram-se em quatro linhas básicas de ação, a saber: abastecimento de água, esgotamento sanitário, saneamento integrado e Projetos Socioeconômicos/Meio ambiente. Para estes foram determinados 3.548 serviços de construção, ampliação, recuperação, entre outros. A primeira obra implementada foi um serviço de saneamento integrado no município de Brumado, em novembro de 2004, concluída 4 anos depois, no valor de R\$ 199.158,87. Ao todo foram calculados investimentos de R\$ $206.500 .872,20$, sendo contratado um valor $14,41 \%$ superior, equivalente a $\mathrm{R} \$ 236.255 .088,20$.

\section{CONCLUSÕES}

Estudos socioeconômicos são instrumentos de apoio ao planejamento que permitem a caracterização de uma determinada região, abordando aspectos multidisciplinares. De forma específica para a gestão de recursos hídricos, a elaboração destes estudos como parte dos Planos de Bacia, enfrenta obstáculos metodológicos relacionados a incompatibilidade territorial dos dados divulgados, ao nível de municípios, e os limites topograficamente estabelecidos para as Bacias. Como resultado, no processo de coleta e seleção dos dados e informações torna-se inevitável enfrentar situações de decisão acerca da exclusão ou manutenção de um determinado município na amostra.

Estas foram algumas das questões metodológicas discutidas no presente trabalho que apresentou critérios simples, flexíveis e transparentes para a delimitação da área de estudo, através de indicadores amplamente divulgados pelos órgãos de estatística nacionais e estaduais. Tal proposição adequa-se especialmente às Bacias Hidrográficas situadas em regiões de menor importância produtiva que não são objeto de estudos dirigidos. Considerando a natureza do objeto tratado, i.é., a gestão de recursos hídricos, optou-se pelo enfoque em critérios populacionais, partindo do princípio de que o abastecimento humano é uso prioritário do recurso, a despeito de toda e qualquer atividade geradora de renda.

As orientações propostas foram ensaiadas na RPGA das Bacias Hidrográficas do Rio das Contas, localizada na porção centro-sul do Estado da Bahia, em uma área de pouca atividade industrial ou agropecuária e baixa densidade populacional. Foram a princípio selecionados 76 municípios com mais de 5\% do território na RPGA, dos quais 39 estão parcialmente inseridos na área de drenagem das Bacias. Estes foram analisados quanto a localização sede, taxa de urbanização e percentual de integração nos limites da Bacia, sendo eliminados outros 10 municípios. 
Para a amostra de 66 municípios selecionados foram coletados dados e informações relacionados ao padrão histórico de ocupação da região evidenciando a pouco significativa presença de atividades industriais associada a baixa produtividade agropecuária. Destaca-se na região projetos e discussões recentes relacionadas a exploração mineral e a construção do Porto Sul, fazendo surgir expectativas diversas relacionadas a geração de trabalho e renda. No âmbito sociodemográfico, as projeções populacionais evidenciam um processo de envelhecimento e urbanização da população nas próximas décadas que pode gerar pressões ainda mais fortes sobre a demanda de serviços básicos como o abastecimento e esgotamento sanitário, cujos indicadores já evidenciam insuficiência e ineficiência.

Observa-se que as informações que puderam ser deduzidas a partir dos dados levantados e estatísticas construídas, utilizando o método de recorte espacial proposto, caracterizam socioeconomicamente a região de forma suficiente para orientar a elaboração de um Plano de Bacia. Ademais, considerando que as orientações não são pautadas pelo determinismo, estas podem ser facilmente revistas ou replicadas em outras Bacias, viabilizando a implantação do processo de gestão de recursos hídricos e dando suporte de conhecimento para decisões básicas envolvendo todos os agentes de uma Bacia Hidrográfica. O exemplo apresentado corrobora essas afirmações.

\section{REFERÊNCIAS}

BARRAQUÉ, Bernard. Subsidiary water in a complex Europe: decision levels, federalism and decentralization. In: FAURE, Alain. Territoires et subsidiarité, l'action publique locale à la lumière d'un principe controversé. Paris: Harmattan, 1997

BISWAS, Asit K. From Mar Del Plata to Kyoto: an analysis of global water policy dialogue. In. Global Enviromental Change, v. 14, pp. 81-88, 2004.

FADUL, Élvia; SILVA, Lindomar Pinto da; CERQUEIRA, Lucas Santos. Políticas e gestão de recursos Hídricos por Comitês de Bacias Hidrográficas: uma análise do Comitê de Bacia Hidrográfica do Recôncavo Norte e Inhambupe. In Bahia Análise \& Dados. Salvador, v. 23, n. 2, p. 409-423, abr/jun, 2013.

FERREIRA FILHO, W. M. Recursos hídricos no Nordeste Semiárido. Brasília: PROJETO ARIDAS RH, SEPLAN/PR, 1994.

HANEMANN, W. Michael. The economic conception of water. In: P.P. Rogers, M.R. Llamas, L. MartinezCortina (Eds.). Water Crisis: myth or reality?. London: Taylor \& Francis plc., 2006. Capítulo 04, p. 61-91.

INSTITUTO BRASILEIRO DE GEOGRAFIA E ESTATÍSTICA - IBGE. Pesquisa Nacional de Saneamento Básico 2008. Rio de Janeiro: IBGE, 2010. Disponível em: http:/www.sidra.ibge.gov.br/bda/ tabela/listabl.asp?c=3939\&z=p\&o=28. Acesso em 10 jan. 2016.

Censo Demográfico 2010. Rio de Janeiro: IBGE, 2011. Disponível em: $\overline{\mathrm{ftp}} / / / \mathrm{ftp}$. ibge.gov.br/Censos/Censo_Demografico_2010/. Acesso em: 10 jan. 2016.

. Pesquisa Pecuária Municipal - PPM. Efetivo dos rebanhos 31/12, por tipo de rebanho. Rio de

Janeiro: IBGE, 2015a. Disponível em: http://www.sidra.ibge.gov.br/bda/ tabela/listabl.asp?c=3939\& $\mathrm{z}=\mathrm{p} \& \mathrm{o}=28$. Acesso em 10 jan. 2016.

Pesquisa Agrícola Municipal - PAM. Rio de Janeiro: IBGE, 2015b. Disponível em:

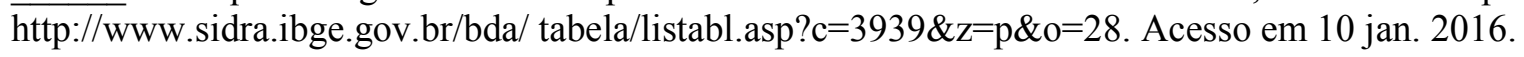

INSTITUTO EUVALDO LODI/NÚCLEO REGIONAL DA BAHIA - IEL. Política Industrial da Bahia: estratégias e proposições. Salvador: Sistema FIEB, vol 1 e 2, 2011.

JANNUZZI, P.M. Indicadores para diagnóstico, monitoramento e avaliação de programas sociais no Brasil. Revista do Serviço Público, Brasília, v.56, n.2, p137- 160, Abr/Jun 2005.

MARCOUILLER, David; COGGINS, Scott. The Economic Value of Water: an introduction. Water Issues in Wisconsin. Madison-WI: UW Extension, G3698-1, 1999a.

How does the market value water resources? Water Issues in Wisconsin. Madison-WI: UW Extension, G3698-2, 1999b.

MOTTA, Ronaldo Seroa da. Economia Ambiental. Rio de Janeiro: Editora FGV, 2006. 226p. 
PORTO, Monica F. A.; PORTO, Rubem la Laina. Gestão de bacias hidrográficas. Estudos Avançados, São Paulo, v. 22, n. 63, p. 43-60, 2008.

RIBEIRO, M. M. R. ; LANNA, A. E. ; PEREIRA, J. S. Elasticidade-preço da demanda e a cobrança pelo uso da água. In: Anais do XIII Simpósio Brasileiro de Recursos Hídricos, Belo Horizonte: ABRH, 1999. (Anais em CD-ROM).

ROGERS, Peter; BHATIA, Ramesh; HUBER, Annete. Water as a social and economic good: how to put the principle into pratice. TAC Background Papers 02. Stockolhlm-Sweden: Global Water Partnership Technical Advisory Commitee, 1998.

SECRETARIA DA INDÚSTRIA COMERCIO E MINERAÇÃO/SUPERINTENDÊNCIA DE DESENVOLVIMENTO INDUSTRIAL E COMERCIAL - SICM/SUDIC. Relatório SUDIC Principais Ações 2009-2012. S.1.: [2013?]. Disponível em: http://www.sicm.ba.gov.br/vs-arquivos/imagens/revista-pdf4536.pdf. Acesso em 09 out 13.

SISTEMA NACIONAL DE INFORMAÇÕES SOBRE SANEAMENTO - SNIS. Diagnóstico de Água e Esgoto. 2013. Disponível em: <http://www.snis.gov.br/>. Acesso em: 15 jul. 2015.

SUPERINTENDÊNCIA DE ESTUDOS ECONÔMICOS E SOCIAIS DA BAHIA - SEI. Dinâmica sociodemográfica da Bahia: 1980-2002. Salvador: SEI, 2003. v.2, Série Estudos e Pesquisas, 60p.

TEIXEIRA, Telma; AZEVEDO, J. P. S. Cobrança pelo uso da água e sustentabilidade da gestão de bacias hidrográficas: uma proposta para a Bacia $\square$ do Rio São Francisco. In Bahia Análise \& Dados. Salvador, v. 23, n. 2, p. 397-408, abr/jun, 2013. 